\title{
Characterization of the product of the gtfS gene of Streptococcus downei, a primer-independent enzyme synthesizing oligo-isomaltosaccharides
}

\author{
R. R. B. Russell, ${ }^{1 *}$ M. L. Gilpin, ${ }^{1} \dagger$ N. Hanada, ${ }^{2}$ Y. Yamashita $^{2}{ }^{2}$ Y. Shibata ${ }^{2}$ \\ and T. TAKEHARA ${ }^{2}$ \\ ${ }^{1}$ Hunterian Dental Research Unit, London Hospital Medical College, London E1 2AD, UK \\ ${ }^{2}$ Department of Preventive Dentistry, Kyushu Dental College, Kokurakita-ku, Kitakyushu 803, Japan
}

(Received 8 January 1990; revised 23 March 1990; accepted 18 April 1990)

\begin{abstract}
The $g t f S$ gene, coding for a glucosyltransferase which synthesizes water-soluble glucan and previously cloned from Streptococcus downei strain MFe28 (mutans serotype $h$ ) into a bacteriophage vector, was subcloned into a plasmid vector. The gtfS gene products expressed in Escherichia coli were compared to the primer-independent, oligoisomaltosaccharide synthase in Streptococcus sobrinus strain AHT (mutans serotype $g$ ) and shown to resemble it closely in molecular mass, isoelectric point, immunological properties, optimum $\mathrm{pH}$ and $K_{\mathrm{m}}$ values. The glucans produced from sucrose by the $g t f S$ gene products are $\alpha$-1,6-linked linear oligo-isomaltosaccharides without any branching sites. A similar $g t f S$ gene was also detected on chromosomal DNA from S. sobrinus strain AHT.
\end{abstract}

\section{Introduction}

Extracellular glucans produced from sucrose by the glucosyltransferases (GTF, EC 2.4.1.5) of oral streptococci are believed to be important in the formation and metabolic activity of dental plaque (Dibdin \& Shellis, 1989; van Houte et al., 1989). In the case of Streptococcus sobrinus, evidence from animal experiments indicates that the synthesis of $\alpha-1,3$-linked glucans is essential for adhesion to smooth tooth surfaces (Loesche, 1986). Although $\alpha$-1,3-linked water-insoluble glucans are the main class of polymer involved in adhesion, $\alpha-1,6$-linked water-soluble glucans are also made. There has been considerable interest in defining the nature of the enzymes involved in the formation of the different types of polymer. Many authors have described distinct enzymes which synthesize insoluble and soluble glucans, designated GTFI and GTFS, respectively (Ciardi, 1983; Mukasa, 1986). Improvements in biochemical separation techniques have allowed several laboratories to purify GTFS enzymes which differ in their isoelectric points, have different requirements for a dextran primer and are also immunologically distinct (Koga et al., 1983; Shimamura et al., 1983; McCabe et al., 1987; Namiki et al., 1985). By applying a combination of column chromatographic and immunosorbent affinity methods

† Present address: School of Life Sciences, Plymouth Polytechnic, Plymouth PL4 8AA, UK.

Abbreviation: GTF, glucosyltransferase(s). one of our laboratories has recently described four distinct GTF enzymes in $S$. sobrinus strain AHT (mutans serotype $g$ ), three of which are forms of GTFS (Hanada \& Takehara, 1987; Yamashita et al., 1989).

Gene-cloning approaches have also demonstrated the existence of multiple $g t f$ genes. There appear to be three gt $f$ genes in Streptococcus mutans (Hanada \& Kuramitsu, 1989 ) and distinct genes have also been cloned from Streptococcus downei strain MFe28 (Gilpin et al., 1985). This organism was originally classified as a strain of $S$. sobrinus, to which it is very closely related (Whiley et al., 1988), and was chosen for the study of GTF because of the extreme 'stickiness' of colonies on sucrosecontaining media and the fact that virtually all of the glucan it makes is water-insoluble (Beighton et al., 1981). Despite this, $S$. downei also possesses GTFS enzymes capable of producing soluble glucans and the gene for one of these ( $g t f S)$ has been cloned and expressed in Escherichia coli (Gilpin et al., 1985; Russell et al., 1987). The enzyme specified by $g t f S$ is primer-independent and makes a water-soluble glucan; we now report a comparison between it and the GTF P2 enzyme (also referred to as GTFSiN) purified from $S$. sobrinus strain AHT (Yamashita et al., 1989).

\section{Methods}

Strains and culture conditions. The bacterial strains used in this study were as follows: Streptococcus downei strain MFe28 (mutans serotype h); Streptococcus sobrinus strain AHT (mutans serotype g); Escherichia 
coli strains DH1, HB101 and JM83. Streptococci were grown anaerobically in Todd-Hewitt broth at $37^{\circ} \mathrm{C}$. E. coli strains were grown aerobically in LB broth (Maniatis et al., 1982) at $37^{\circ} \mathrm{C}$.

DNA manipulation. DNA isolation, restriction endonuclease digestions, ligation, and transformation of competent $E$. coli cells were done as recently described (Maniatis et al., 1982; Aoki et al., 1986; Russell et al., 1987).

Cloning of gtfS from $S$. downei. The gtfS gene of $S$. downei was originally cloned in a recombinant bacteriophage $\lambda$ (designated $\lambda \mathbf{M} 7$ ) which produced plaques which formed a soluble glucan when plated on $E$. coli growing on sucrose-containing medium (Gilpin et al., 1985). Restriction enzyme mapping of bacteriophage $\lambda M 7$ showed that the total cloned insert was $12.6 \mathrm{kbp}$ in length. DNA purified from bacteriophage $\lambda M 7$ was partially digested with restriction endonuclease EcoRI and ligated by T4 DNA ligase to DNA from plasmid pACYC184, also cleaved with EcoRI. The ligation mixture was used to transform $E$. coli strain $\mathrm{DH} 1$ and transformants were selected on LB agar plates containing tetracycline $\left(15 \mu \mathrm{g} \mathrm{m}^{-1}\right)$. Transformants containing inserts in the chloramphenicol-resistance gene of the vector plasmid were detected as chloramphenicol-sensitive colonies by replica-plating on medium containing chloramphenicol $\left(25 \mu \mathrm{g} \mathrm{ml}^{-1}\right)$. It was not possible to detect any recombinant clones expressing GTF activity by using the sucrose-indicator medium previously used for subcloning the $S$. downei gtfI gene (Russell et al., 1987), but GTFactive clones were detected by a small-scale assay for the release of reducing sugar from sucrose (Aduse-Opoku et al., 1989) and by reactivity in Western blots with a rabbit antiserum raised against GTF purified from lysates of $E$. coli infected with bacteriophage $\lambda \mathrm{M} 7$ by methods described by Russell et al. (1987). One recombinant plasmid, designated pMLG60, was selected for further study.

Cloning of gtf $S$ gene from $S$. sobrinus. A rabbit antiserum raised against GTF P2, purified from culture supernatant fluid of $S$. sobrinus strain AHT (Yamashita et al., 1988) was used to isolate recombinants carrying the gene coding for GTF P2 from a $S$. sobrinus strain AHT gene clone bank. Chromosomal DNA from $S$. sobrinus strain AHT was partially digested with Sau3AI and ligated into BamHI-cleaved plasmid pUC18. The ligation mixtures were transformed into $E$. coli strain JM83 and recombinant clones were screened with the antiserum directed against GTF P2. One clone which reacted positively with the antiserum was identified and designated strain YS689 (E. coli strain JM83 carrying the chimaeric pYS689). This strain exhibited neither GTF nor sucrase activity.

Enzyme assay. Sucrase activity was determined by the Somogyi procedure for assaying reducing sugars (Somogyi, 1945). GTF activity was determined by measuring glucan product with a modification of the anthrone method (Halhoul \& Kleinberg, 1972) or by a spectrophotometric method for glucose and fructose using an F-kit (Boehringer Mannheim). The optimum pH was determined using sodium acetate buffers for the $\mathrm{pH}$ range $4 \cdot 0-6 \cdot 5$ and Tris/ $\mathrm{HCl}$ buffers for the $\mathrm{pH}$ range $6 \cdot 5-8 \cdot 0 . K_{\mathrm{m}}$ values of the enzymes were determined using the anthrone method as previously described (Hanada et al., 1987) or with an F-kit (Yamashita et al., 1989), in both cases using an incubation period of $1 \mathrm{~h}$.

Electrophoresis. Proteins were analysed by SDS-PAGE as previously described by Aoki et al. (1986). Prestained molecular mass markers were from Bio-Rad. DNA fragments were analysed on 0.5 or $0.7 \%$ (w/v) agarose gels with Tris/borate/EDTA buffer, pH 8.3 (Maniatis $e t$ al., 1982).

Western and Southern blot analysis. Western blot analysis was done as described by Towbin et al. (1979). Southern blot analysis was done as described by Maniatis et al. (1982). Separate samples of chromosomal DNA extracted from $S$. sobrinus strain AHT were digested to completion with different restriction endonucleases; the fragments were separated by electrophoresis and transferred to nitrocellulose paper. The hybridization probes used consisted of DNA of plasmids pMLG60 and pYS689, labelled with biotin by nick-translation according to the instruction of the supplier of the DNA detection system (Bethesda Research Laboratories).

Localization of the gtfS gene product. E. coli strain HB101 carrying plasmid pMLG60 was grown in LB broth $(10 \mathrm{ml})$ and harvested by centrifugation at $4000 \mathrm{~g}$ for $5 \mathrm{~min}$. Subcellular fractions were isolated as described by Heppel (1971). The periplasmic fraction was obtained as the cold osmotic shock fluid. After osmotic shock, the cells were washed twice with $10 \mathrm{mM}-\mathrm{Tris} / \mathrm{HCl}$ buffer $(\mathrm{pH} \mathrm{7 \cdot 0})$, suspended in the same buffer with Ballotini beads $(0.3 \mathrm{~mm}$ diameter $)$, and disrupted at full power in a Vibrogen cell mill (Edmund Buhler) for $30 \mathrm{~min}$ at $4{ }^{\circ} \mathrm{C}$. After centrifugation at $10000 \mathrm{~g}$ for $30 \mathrm{~min}$ at $4{ }^{\circ} \mathrm{C}$, the supernatant fluid was utilized as the cytoplasmic fraction. The activities of GTF, the cytoplasmic marker $\beta$-galactosidase (EC 3.2.1.23) and the periplasmic marker alkaline phosphatase (EC 3.1.3.1) were determined in each fraction (Heppel, 1971).

Purification of the gtfS gene product. E. coli strain HB101 carrying pMLG60 was harvested after $16 \mathrm{~h}$ growth in 21 of LB broth by centrifugation at $4000 \mathrm{~g}$ for $5 \mathrm{~min}$ at $37^{\circ} \mathrm{C}$. The cell pellet was suspended with $50 \mathrm{~mm}$-sodium acetate buffer (pH 6.0) containing $0.1 \mathrm{~mm}$-phenylmethylsulphonyl fluoride. The cells were disrupted as above for $30 \mathrm{~min}$ in the cell mill with Ballotini beads. After removal of the beads, the suspension was ultracentrifuged at $100000 \mathrm{~g}$ in a Hitachi $55 \mathrm{P}-72$ centrifuge with a RP40-958 rotor for $60 \mathrm{~min}$. The supernatant fluid was concentrated by precipitation with ammonium sulphate $(50 \%$ saturation). After centrifugation at $10000 \mathrm{~g}$ for $30 \mathrm{~min}$, the pellet was redissolved in $50 \mathrm{~mm}$-sodium acetate buffer ( $\mathrm{pH} \mathrm{6.0)}$ ) and applied to a Butyl Toyopearl (TOSOH, Tokyo) hydrophobic interaction column equilibrated with the same buffer. The gel bed was washed extensively with the same buffer. Adsorbed material was then eluted with a linear gradient of increasing ethylene glycol concentration to $60 \%(\mathrm{v} / \mathrm{v})$ in the $50 \mathrm{~mm}$-sodium acetate buffer ( $\mathrm{pH} \mathrm{6 \cdot 0)}$. The GTF-active fractions were dialysed against the $50 \mathrm{~mm}$-sodium acetate buffer (pH 6.0) and used as the soluble GTF fraction. After the above ultracentrifugation step was applied to the disrupted $E$. coli cells, the pellet was washed by resuspension in $50 \mathrm{~mm}$-sodium acetate buffer containing $1 \%(\mathrm{w} / \mathrm{v})$ Triton X-100. Following a further ultracentrifugation step, the washing by resuspension and ultracentrifugation was repeated and finally the washed pellet was suspended in $50 \mathrm{~mm}$-sodium acetate buffer and used as the envelope-associated GTF fraction.

Preparation of GTF P2. The purification and properties of GTF P2 from $S$. sobrinus strain AHT have recently been presented in detail by Yamashita et al. (1989).

Preparation of antisera. Strain AHT of $S$. sobrinus secretes four distinct GTF (Takehara et al., 1984). These enzymes were separated by DEAE-cellulose ion-exchange chromatography and the four GTF designated P1, P2, P3 and P4 by their order of elution from the DEAEcellulose column. Each of the four purified extracellular GTF polypeptides from $S$. sobrinus strain AHT was mixed with an equal volume of Freund's incomplete adjuvant and injected intradermally into rabbits. The animals received three injections of antigen (approx. $100 \mu \mathrm{g}$ per dose) at intervals of a week and antisera were collected fror ear veins $10 \mathrm{~d}$ after the final injection.

Glucan analysis. The glucans produced by $g$ t $f S$ gene products located in the soluble and envelope-associated fractions of disrupted cells of $E$. coli strain HB101 carrying pMLG60 were prepared by $18 \mathrm{~h}$ incubation of appropriate amounts of each enzyme in $50 \mathrm{~mm}$-sodium acetate buffer ( $\mathrm{pH} 6.0)$ containing $5 \%(\mathrm{w} / \mathrm{v})$ sucrose and $5 \mathrm{~mm}-\mathrm{NaF}$. The glucans were precipitated with $80 \%(\mathrm{v} / \mathrm{v})$ ethanol, harvested by 
centrifugation at $8000 \mathrm{~g}$ for $15 \mathrm{~min}$, and washed twice with $80 \%(\mathrm{v} / \mathrm{v})$ ethanol. The glucans were analysed by the anthrone method and their molecular masses determined by HPLC using a TSK-gel G2500PW column (TOSOH). To analyse the result of treating the glucans with glucodextranase (glucan 1,6- $\alpha$-glucosidase, EC 3.2.1 .70) from Arthrobacter globiformis (Funakoshi, Tokyo), glucans were digested with the glucodextranase in $50 \mathrm{~mm}$-sodium acetate buffer $(\mathrm{pH} 6.0)$ for $12 \mathrm{~h}$. The products of the glucodextranase digestion were analysed by HPLC with an HPX-42A column (Bio-Rad) warmed to $80^{\circ} \mathrm{C}$ and with a flow rate of $0.8 \mathrm{ml} \mathrm{min}{ }^{-1}$. Carbohydrates were detected by a refractometer RI- 8 (TOSOH). Molecular size markers for oligo-isomaltosaccharides were from BioCarb Chemicals.

\section{Results}

\section{Subcloning the $S$. downei gtf S gene on to a plasmid}

The gtf $S$ gene was subcloned from bacteriophage $\lambda \mathrm{M} 7$ into pACYC184 to form recombinant pMLG60. The cloned insert could be stably maintained and a partial restriction endonuclease cleavage map is shown in Fig. 1. Further attempts to reduce the size of the insert revealed that the presence of the $1.7 \mathrm{kbp} E c o$ RI fragment did not affect the amount or the physical properties of GTF produced in recombinant $E$. coli strains. Thus, the gtf $S$ gene can be concluded to be located on the $6.0 \mathrm{kbp} E c o$ RI fragment. Since approximately $5.0 \mathrm{kbp}$ of DNA is required to code for a protein the size of GTF, pMLG60 can carry only a single intact $g t f$ gene.

\section{Partial purification of the gtfS gene products}

Fractionation of crude extracts from E. coli strain HB101 carrying pMLG60 revealed that the majority $(73 \%)$ of the GTF activity was found in the envelope-associated fraction, compared to only $22.5 \%$ in the soluble cytoplasmic fraction and only $4.5 \%$ in the periplasmic fraction.

The soluble fraction of the GTF activity expressed in $E$. coli strain HB101 carrying pMLG60 was partially purified following ammonium sulphate precipitation and Butyl Toyopearl hydrophobic interaction chromatography. In an effort to purify the GTF in the envelope fraction, the non-ionic detergent Triton X-100 was used; however, even after Triton extraction $82 \%$ of the activity initially detected in this fraction remained. Aoki et al. (1986) also found that the cloned $S$. mutans $g$ tf $B$ enzyme was localized in the membrane fraction of $E$. coli. Indirect evidence suggests that this membrane binding is

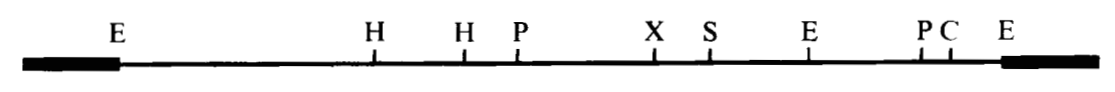

peptide in secretion signa peptide in the heterologous system, not to intrinsic properties of the GTF (which are predominantly hydrophilic).

The GTF activity expressed in E. coli strain HB101 carrying pMLG60 resembled that previously characterized in lysates of $E$. coli infected with recombinant bacteriophage $\lambda \mathrm{M} 7$ carrying the $\mathrm{gtf} S$ gene in possessing a molecular mass of $150 \mathrm{kDa}$, being primer-independent and forming a soluble glucan product from sucrose (Table 1). No detectable water-insoluble glucan was detected by the anthrone method following $18 \mathrm{~h}$ incubation. Kinetic studies of the enzyme specified by the gtf $S$ gene revealed that the optimum $\mathrm{pH}$ was about 6.0 and $K_{\mathrm{m}}$ values for sucrose were approximately $154 \mathrm{mM}$ assayed by the anthrone method or $24 \mathrm{~mm}$ assayed using an F-kit.

\section{Glucan analysis}

HPLC analysis of the glucans synthesized by the GTF activity expressed in $E$. coli strain $\mathrm{HB} 101$ carrying pMLG60 using a TSK-gel G2500PW column indicated that both soluble and envelope-associated enzymes produced low-molecular-mass glucans. The degrees of polymerization of the products were less than 30 (Fig. 2), and did not increase even with extended incubation (data not shown). Thus, the GTF enzyme specified by the cloned gtf $S$ gene closely resembles the GTF P2 enzyme (primer-independent, oligo-isomaltosaccharide synthase; GTFSiN) purified from $S$. sobrinus strain AHT by Yamashita et al. (1989), since it synthesized oligo-isomaltosaccharides exclusively.

While soluble and envelope-associated fractions from recombinants expressing gtfS and purified GTF P2 from $S$. sobrinus strain AHT all produced oligoisomaltosaccharides, the other GTF enzymes producing soluble glucans, i.e. GTF P1 (primer-independent, water-soluble glucan synthase; GTFSi) and GTF P4 (primer-dependent, water-soluble glucan synthase; GTFSd) all produce extremely high-molecular-mass glucans (Takehara et al., 1984; Yamashita et al., 1989).

Fig. 3 shows the elution profile of the products formed

Fig. 1. Partial restriction enzyme cleavage map of recombinant pMLG60. pMLG60 contains a $7.7 \mathrm{kbp}$ EcoRI fragment of $S$. downei DNA bearing the gtf $S$ gene subcloned from bacteriophage $\lambda \mathrm{M} 7$ inserted into the $E c o$ RI site of vector pACYC184. The vector pACYC184 DNA is indicated by the thick line and the approximate location of the gtf $S$ gene indicated by the dotted line. E, EcoRI; H, HindIII; P, PstI; X, XbaI; S, SacI; C, ClaI. 


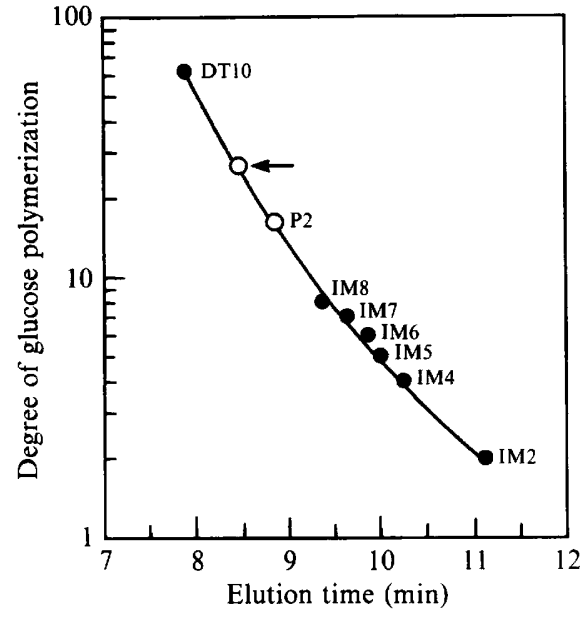

Fig. 2. Molecular mass of glucans produced by envelope-associated and soluble fractions of $E$. coli strain HB101 carrying pMLG60 bearing the gtfS gene (arrow) and purified $S$. sobrinus GTF P2. The glucans were analysed by HPLC using a TSK-gel G2500PW column. Standard glucans were dextran T10, (DT10, molecular mass 10000) and isomaltosaccharides with degrees of glucose polymerization from two to eight (IM2-IM8).

Table 1. Physical and kinetic properties of different primerindependent GTFS enzymes

GTF P1 and GTF P2 from $S$. sobrinus were described by Hanada et al. (1987) and Yamashita et al. (1989) respectively. The $\mathrm{pI}$ and primer-independency of GTFS from $S$. downei were described by Russell et al. (1987); other data are from this paper.

\begin{tabular}{lccc}
\hline \hline & \multicolumn{3}{c}{ GTF } \\
\cline { 2 - 4 } \multicolumn{1}{c}{ Characteristic } & GTF P1 & GTF P2 & GTFS* \\
\hline$M_{\mathrm{r}}$ & $135 \mathrm{kDa}$ & $152 \mathrm{kDa}$ & $148 \mathrm{kDa}$ \\
$K_{\mathrm{m}}$ value & $130 \mathrm{kDa}$ & $137 \mathrm{kDa}$ & \\
& $3.9 \mathrm{mM} \dagger$ & $145 \mathrm{mM} \dagger$ & $154 \mathrm{mM} \dagger$ \\
pI & & $25 \mathrm{mM} \ddagger$ & $24 \mathrm{mM} \ddagger$ \\
Optimal pH & $5 \cdot 8$ & $5 \cdot 5,6 \cdot 1$ & $5 \cdot 5$ \\
Primer-dependency & Independent & Independent & $6 \cdot 0$ \\
Glucan (degrees of & Extremely high & & \\
glucose polymerization) & molecular mass & $\sim 15$ & $\sim 27$ \\
\hline \hline
\end{tabular}

- Envelope fraction of $E$. coli strain HB101 carrying pMLG60.

$\dagger K_{\mathrm{m}}$ value determined by the anthrone method.

$\ddagger K_{\mathrm{m}}$ value determined by the use of an F-kit.

from the glucan made by GTFS after digestion with glucodextranase (exodextranase). Commercial dextran T10 was only partially digested by glucodextranase, since $\alpha-1,3,6$ branching sites are present and enzyme activity of the glucodextranase is disturbed at branching sites on glucans. On the other hand, the glucans produced by

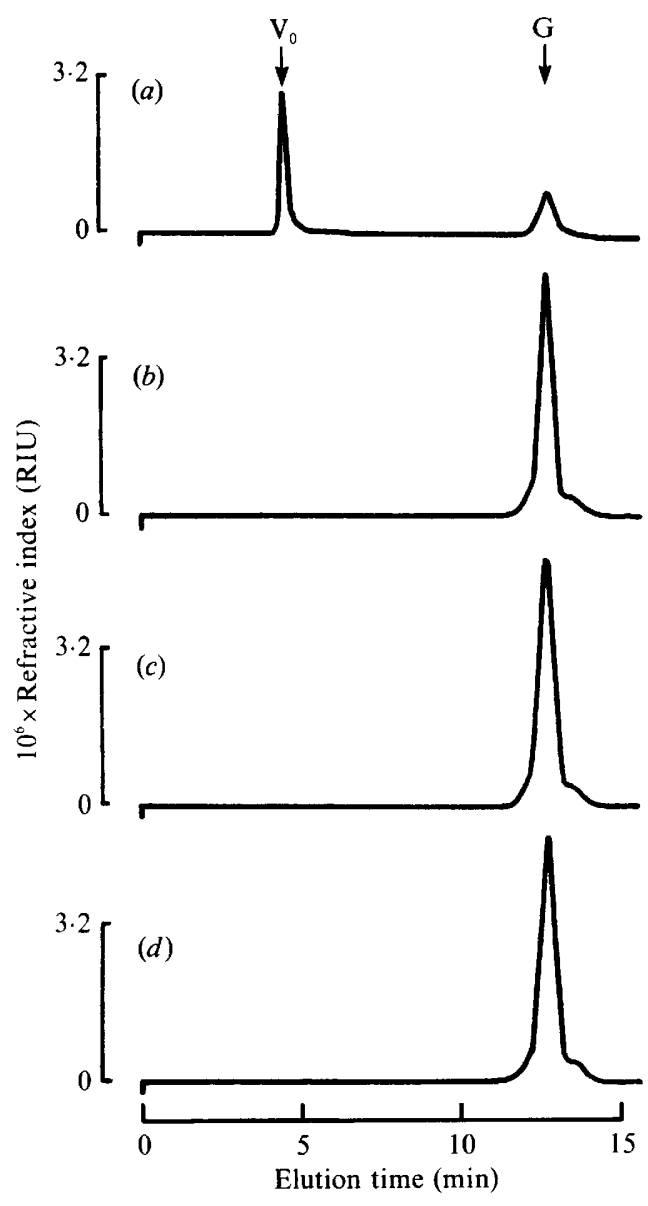

Fig. 3. HPLC analysis of the products of hydrolysis of glucans with glucodextranase. Degraded glucans were analysed by HPLC using an HPX-42A column. (a) Dextran T10; (b) glucan synthesized by $S$. sobrinus GTF P2; (c) glucan synthesized by $E$. coli strain $\mathrm{HB} 101$ carrying pMLG60 (envelope fraction); (d) glucan synthesized by $E$. coli strain HB101 carrying pMLG60 (soluble fraction). $\mathrm{V}_{0}$, void volume; $\mathrm{G}$, glucose; RIU, refractive index unit.

soluble and envelope-associated GTF from recombinants harbouring the gt $f S$ gene, and by purified GTF P2 were all totally digested to glucose by glucodextranase, indicating the absence of branch-points.

\section{Western blot analysis}

Confirmation of the identity of the $S$. downei gtf $S$ gene product and $S$. sobrinus GTF P2 (GTFSiN) was provided by the observation that a band of $148 \mathrm{kDa}$ present in the envelope-associated fraction of $E$. coli strain HB101 carrying pMLG60 reacted with antiserum raised against GTF P2 (Fig. 4). The antiserum also detected somewhat smaller protein bands in the soluble fraction $(138 \mathrm{kDa}$ and $97 \mathrm{kDa}$ ). 


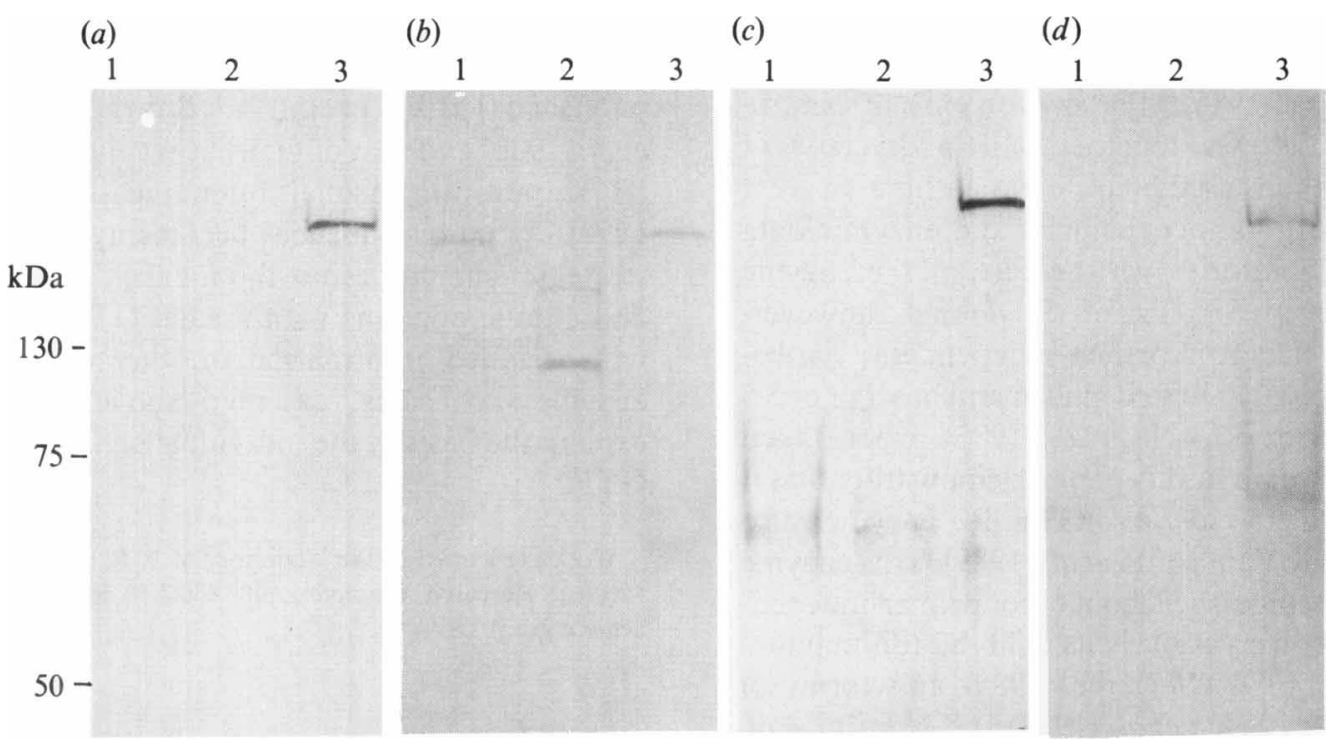

Fig. 4. Western blot analysis of proteins specified by the cloned $g t f S$ gene. (a) Antiserum against GTF P1, (b) antiserum against GTF P2, (c) antiserum against GTF P3, (d) antiserum against GTF P4. Lanes: 1, E. coli strain HB101 carrying pMLG60 (envelope fraction); 2, E. coli strain HB101 carrying pMLG60 (soluble fraction); 3, S. sobrinus strain AHT culture supernatant fluid. Positions of prestained molecular mass markers are indicated at the left.

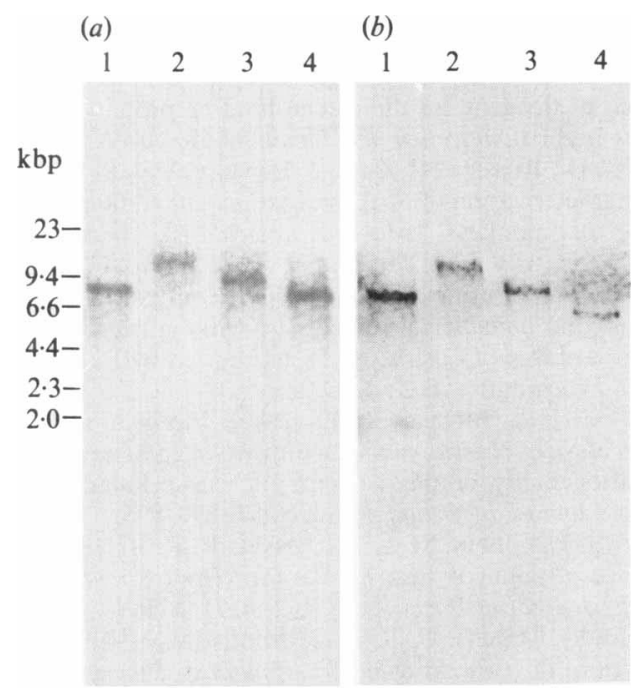

Fig. 5. Southern blot analysis of $S$. sobrinus strain AHT chromosomal DNA. The DNA was cleaved with restriction endonucleases EcoRI (lane 1), BamHI (lane 2), HindIII (lane 3) and SacI (lane 4), (a) pMLG60, carrying the $S$, downei gtf $S$ gene, was used as probe; (b) pYS689, carrying cloned insert from $S$. sobrinus strain AHT was used as probe. Molecular size markers are indicated at the left.

Although all four antisera raised against GTF P1 to P4 reacted with the positive controls ( $S$. sobrinus strain AHT culture supernatant fluid), only antiserum to GTF P2 reacted with both soluble and envelope-associated fractions obtained from E. coli strain HB101 carrying pMLG60.

\section{Southern blot analysis}

To investigate the relationship between the $S$. downei gtf $S$ gene cloned in pMLG60 and genes in $S$. sobrinus strain AHT, Southern blot analysis was done. As shown in Fig. 5, the DNA probe made from pMLG60 hybridized to only one fragment of $S$. sobrinus strain AHT chromosomal DNA cleaved with any of the restriction endonucleases EcoRI, BamHI, HindIII or SacI. The probe made from DNA of pYS689 showed an identical hybridization pattern to that of the probe made from pMLG60, indicating that they were both recognizing the same gtfS gene. This result is in agreement with previous reports of the close relationship of $g t f$ genes from $S$. sobrinus and $S$. downei (Russell et al., 1987, 1988).

\section{Discussion}

The GTF enzymes which have been purified from different streptococci (and also from Leuconostoc spp.) are ail of similar molecular mass $(150-170 \mathrm{kDa})$, but show considerable variation in the types of linkage they introduce into glucans, their need for a primer, their isoelectric points, their $K_{\mathrm{m}}$ values for sucrose, the avidity with which they bind to preformed glucans and their immunological specificity. It has become apparent that the isoelectric point of each GTF is one of the most useful parameters for distinguishing GTF, although care must be taken to ensure that $\mathrm{pI}$ values are determined with an 
undegraded form of the enzyme as even a slight drop in molecular mass can drastically alter the pI (Yamashita $e t$ al., 1989; Mukasa, 1986). These problems of heterogeneity and breakdown, together with a diversity of experimental methods used by different authors, make it difficult to compare physicochemical and enzymic data from different laboratories. In the case of the enzyme specified by the gtfS gene of $S$. downei, however, previous reports that it is primer-independent, synthesizes water-soluble $\alpha-1,6$-linked glucan and has a pI of $5 \cdot 5$ (Gilpin et al., 1985; Russell et al., 1987), when taken together with new data in this paper, demonstrate that it corresponds to the $S$. sobrinus GTF P2 enzyme, also named GTFSiN by Yamashita et al. (1989). This enzyme is most readily distinguished from other primer-independent enzymes, known variously as GTF-S2 (Shimamura et al., 1983), GTF-S4 (McCabe, 1985) and forms of GTFS described by Koga et al. (1983) and Namiki et al. (1985), by the fact that it makes only a short oligosaccharide of not more than 30 glucose units, whereas the others make polymers of very high molecular mass. Kinetic parameters such as $K_{\mathrm{m}}$ are not readily amenable to comparisons because of the several reactions catalysed by GTF (polymer formation, sucrose hydrolysis and transglycosylation) and the different assays used. The availability of specific immunological and genetic means for identifying GTF should help to resolve some of the confusion in the literature.

Despite definite advances in biochemical and genetic studies of various different GTF, there is as yet no information available on the location of the active sites of the GTF, nor of the features which determine interaction with primer or the type of linkage formed. Molecular genetic methods are providing an alternative approach to these problems. In those cases where nucleotide sequences and deduced amino acid sequences of GTF have been determined, extensive homology between different enzymes has been observed. This homology is seen both between GTF from a single species (Ueda et al., 1988) and between GTF from different species (Russell et al., 1988). A striking feature of all the sequences determined to date is the occurrence of a region of repeat sequences at the C-terminal end of the enzymes, which may be related to their ability to bind to glucans (Banas et al., 1990), although in vitro deletions of the $S$. downei gtf I gene showed that a substantial part of the C-terminal region of the enzyme could be removed without loss of GTF activity (Ferretti et al., 1987). These deletion mutants mimic the widely observed degraded forms of GTF, which retain glucan-forming activity. Site-directed mutagenesis of $g t f$ genes is a possible means for locating active sites of these enzymes, although the high molecular masses of GTF makes this a daunting task. Comparisons between amino acid se- quences of different GTF should also be informative. The sequences of three GTF have already been published (Ferretti et al., 1987; Shiroza et al., 1987; Ueda et al., 1988) and that of $g t f S$ has recently been completed (H. Kuramitsu, personal communication; Gilmore et al., 1990). As more sequences become available, alignment strategies should permit the identification of conserved and unique domains within each GTF which, together with detailed information on the properties of each enzyme such as is presented above, will allow us to explain the basis of the individual characteristics of each GTF.

Work performed in the laboratory of R.R.B.R. was supported by Medical Research Council grant 8504830 and US Public Health Service grant DE08191.

\section{References}

Aduse-OpoKu, J., Gilpin, M. L. \& Russell, R. R. B. (1989). Genetic and antigenic comparison of Streptococcus mutans fructosyltransferase and glucan-binding protein. FEMS Microbiology Letters 59, 279-282.

Aoki, H., Shiroza, T., Hayakawa, M., Sato, S. \& Kuramitsu, H. K. (1986). Cloning of a Streptococcus mutans glucosyltransferase gene coding for insoluble glucan synthesis. Infection and Immunity 53, 587-594.

Banas, J. A., Russell, R. R. B. \& Ferretti, J. J. (1990). Sequence analysis of the gene for the glucan-binding protein of Streptococcus mutans Ingbritt. Infection and Immunity 58, 667-673.

Beighton, D., Russell, R. R. B. \& Hayday, H. (1981). The isolation and characterization of Streptococcus mutans serotype $h$ from dental plaque of monkeys (Macaca fascicularis). Journal of General Microbiology 124, 271-279.

CIARDI, J. (1983). Purification and properties of glucosyltransferases of Streptococcus mutans: a review. In Glucosyltransferases, Glucans, Sucrose and Dental Caries, pp. 51-64. Edited by R. J. Doyle \& J. E. Ciardi. Washington, DC: IRL Press.

Dibdin, G. H. \& Shellis, R. P. (1989). Physical and biochemical studies of Streptococcus mutans sediments suggest new factors linking the cariogenicity of plaque with its extracellular polysaccharide content. Journal of Dental Research 67, 890-895.

Ferretti, J. J., Gilpin, M. L. \& Russell, R. R. B. (1987). Nucleotide sequence of a glucosyltransferase gene from Streptococcus sobrinus MFe28. Journal of Bacteriology 169, 4271-4278.

Gilpin, M. L., Russell, R. R. B. \& MoRRISSEY, P. (1985). Cloning and expression of two Streptococcus mutans glucosyltransferases in Escherichia coli K-12. Infection and Immunity 49, 414-416.

GiLmore, K. S., Russell, R. R. B. \& Ferretti, J. J. (1990). Analysis of the Streptococcus downei $g t f S$ gene, which specifies a glucosyltransferase that synthesizes soluble glucans. Infection and Immunity $\mathbf{5 8}$, in the Press.

Halhoul, M. N. \& Kleinberg, I. (1972). Differential determination of glucose and fructose, and glucose- and fructose-yielding substances, with anthrone. Analytical Biochemistry 50, 337-343.

HANADA, N. \& KURAMITSU, H. K. (1989). Isolation and characterization of the Streptococcus mutans gtfD gene, coding for primerdependent soluble glucan synthesis. Infection and Immunity 57, 2079-2085.

HaNADA, N. \& TAKeHaRa, T. (1987). Comparison of different watersoluble glucan synthases from Streptococcus mutans serotype $g$. Microbios 50, 147-152.

Hanada, N., Takehara, T. \& Saeki, E. (1987). Purification and characterization of a third glucosyltransferase from Streptococcus mutans serotype $g$. Journal of General Microbiology 133, 1351-1358. 
HePPEL, L. A. (1971). The concept of periplasmic enzymes. In Structure and Function of Biological Membranes, pp. 223-247. Edited by L. I. Rothfield. New York: Academic Press.

van Houte, J., Russo, J. \& Prostak, K. S. (1989). Increased pH-lowering ability of Streptococcus mutans cell masses associated with extracellular glucan-rich matrix material and the mechanisms involved. Journal of Dental Research 68, 451-459.

Koga, T., SATo, S., YakushiJI, T. \& INOUE, M. (1983). Separation of insoluble and soluble glucan-synthesising glucosyltransferases of Streptococcus mutans OMZ176 (serotype d). FEMS Microbiology Letters 16, 127-130.

LOESCHE, W. J. (1986). Role of Streptococcus mutans in human dental decay. Microbiological Reviews 50, 353-380.

Maniatis, T., Fritsch, E. F. \& Sambrook, J. (1982). Molecular Cloning: a Laboratory Manual. Cold Spring Harbor, NY: Cold Spring Harbor Laboratory.

MCCABE, M. M. (1985). Purification and characterization of a primerindependent glucosyltransferase from Streptococcus mutans 6715-13 mutant 27. Infection and Immunity 50, 771-777.

MCCABE, M. M., AlberTs, M. \& STEIN, J. (1987). Monoclonal antibodies to the extracellular glucosyltransferases from Streptococcus sobrinus 6715. Infection and Immunity 55, 1900-1905.

MUKaSA, H. (1986). Properties of Streptococcus mutans glucosyltransferases. In Molecular Microbiology and Immunobiology of Streptococcus mutans, pp. 121-132. Edited by S. Hamada, S. M. Michalek, H. Kiyono, L. Menaker \& J. R. McGhee. Amsterdam: Elsevier.

Namiki, Y., Kantake, I., Ikeda, T. \& Fuxushima, K. (1985). Separation of three kinds of glucosyltransferases from Streptococcus mutans strain B13. IRCS Medical Science 13, 501-502.

Russell, R. R. B., Gilpin, M. L., Mukasa, H. \& Dougan, G. (1987). Characterization of glucosyltransferase expressed from a Streptococcus sobrinus gene cloned in Escherichia coli. Journal of General Microbiology 133, 935-944.
Russell, R. R. B., Shiroza, T., Kuramitsu, H. K. \& Ferretti, J. J. (1988). Homology of glucosyltransferase gene and protein sequences from Streptococcus sobrinus and Streptococcus mutans. Journal of Dental Research 67, 543-547.

Shimamura, A., Tsumori, H. \& Mukasa, H. (1983). Three kinds of glucosyltransferases from Streptococcus mutans 6715 (serotype g). FEBS Letters 157, 79-84.

Shiroza, T., Ueda, S. \& Kuramitsu, H. K. (1987). Sequence analysis of the gtfB gene from Streptococcus mutans. Journal of Bacteriology $169,4263-4270$.

Somogyi, M. (1945). A new reagent for the determination of sugars. Journal of Biological Chemistry 160, 61-68.

TAKehara, T., HANADA, N. \& SAEKI, E. (1984). Interaction of glucosyltransferase isozymes on glucan synthesis by Streptococcus mutans AHT (serotype g). Microbios Letters 27, 113-120.

Towbin, H., Staehelin, T. \& GoRdon, J. (1979). Electrophoretic transfer of proteins from polyacrylamide gels to nitrocellulose sheets: procedure and some applications. Proceedings of the National Academy of Sciences of the United States of America 76, 4350-4354.

Ueda, S., Shiroza, T. \& Kuramitsu, H. K. (1988). Sequence analysis of the gtfC gene from Streptococcus mutans GS-5. Gene 69, 101-109.

Whiley, R. A., Russell, R. R. B., Hardie, J. M. \& Beighton, D. (1988). Streptococcus downei (sp. nov.): for strains previously described as Streptococcus mutans serotype $h$. International Journal of Systematic Bacteriology 38, 25-29.

Yamashita, Y., Hanada, N. \& Takehara, T. (1988). A novel glucosyltransferase from Streptococcus mutans produces oligoisomaltosaccharides. Biochemical and Biophysical Research Communications 150, 687-693.

Yamashita, Y., Hanada, N. \& Takehara, T. (1989). Purification of a fourth glucosyltransferase from Streptococcus sobrinus. Journal of Bacteriology 171, 6265-6270. 